\title{
Laboratory tests of soil-shell structures made of GRP - an evaluation of the soil medium
}

\author{
Tomasz Abel ${ }^{1, *}$ \\ ${ }^{1}$ Wrocław University of Science and Technology, Faculty of Civil Engineering, Department of \\ Mechanics of Structures and Urban Engineering, Poland
}

\begin{abstract}
Soil-shell structures have been widely used for many years in road and network constructions where there are collisions of transport linear structures. A benefit of using such structures is the speed of construction and the durability of the materials used. Despite the wide use of different types of materials, in particular steel shells, new material solutions are still being sought. One material that has been used successfully for many years in the construction of underground network facilities is plastic from the group of duroplasts. Composite profiles with cross-sections reaching up to $3.0 \mathrm{~m}$ can be used in the construction of pipe culverts. These culverts are not only objects with a circular cross-section shape, but also other shapes with very good hydraulic parameters and high strength parameters. In order to determine the dependence between the strength of a composite shell and the surrounding soil, a series of tests of laboratory models made in a natural scale were carried out. The aim of the research was to determine the possibility of using duroplastic structures as culverts located under traffic routes, and to also determine the scope of cooperation of the structure with the soil medium and their mutual dependencies.
\end{abstract}

\section{Introduction}

Soil-shell structures, which qualify as susceptible constructions, are commonly used in transport engineering [1]. Pipes and other profiles made of GRP (duroplasts reinforced with glass fiber) have been widely used for many years in the construction of underground gravity and pressure networks. In addition, GRP pipes, due to their high material and strength parameters, can be used as jacking pipes when constructing underground structures using trenchless methods e.g. microtunneling [2].

Glass fiber reinforced polymers are characterized with high mechanical strength, low density, dimensional stability and good heat resistance. These properties depend on the type and content of fiber, its form and the adhesion of the polymer matrix. This is due to the fact that polymers are isotropic and viscoelastic, while fibers are anisotropic and have elastic properties [3]. Circular modules made of GRP are manufactured with a stiffness of SN2500, SN5000, SN10000, while the bending strength values of non-circular profiles correspond to the minimum stiffness required for circular cross-sections. The obtained

\footnotetext{
${ }^{*}$ Corresponding author: tomasz.abel@pwr.edu.pl
} 
values enable the direct implementation of this type of material in the soil medium (see Photo 1).

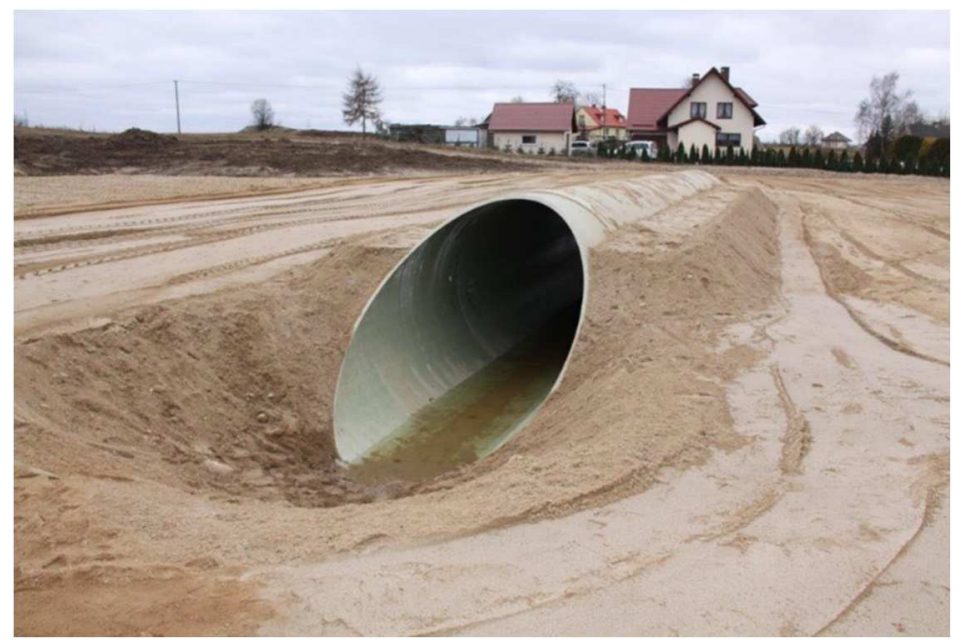

Photo 1. A culvert during construction [4].

\section{Calculation methods}

In the currently used calculation methods, the basic parameter that determines the scope of cooperation of an object with the soil medium is the stiffness of the structure's material. The basic materials can be distinguished as rigid and susceptible.

Rigid conduits, which are immersed in the soil and made of traditional materials such as concrete, reinforced concrete or stoneware, only deform under the influence of loads acting on them to a limited degree. The lack of cross-section deformation means that the distribution of loads is characterized by large concentrations in the upper and lower cross-section areas, especially when soil is poorly compacted in the side zones of the excavation. Such a distribution of loads is very unfavorable due to the fact that the bending moments in the most strenuous cross-sections have extreme values. The state of maximum concentration of loads occurs immediately after covering the excavation and removing its casing.

Susceptible materials that are arranged in trenches behave differently. These include duroplasts, which are the subject of the paper. Due to their flexibility, they interact with the surrounding soil medium during the transferring of loads. Therefore, when dimensioning such objects, the work of the elements on their own is not considered, but the work of the "construction - soil medium" system is. Distributions of loads acting on such objects are characterized by high uniformity, and the internal force distributions caused by them are very beneficial for the analyzed structure. This is because the values of extreme bending moments clearly decrease in relation to analogues ones in rigid conduits [3].

The basis for cooperation (interaction) of the "construction - soil" system (hence an analogy to the soil-shell constructions) is the deformation of the loaded structure's crosssection and the soil reaction corresponding to it. Under the influence of vertical pressure, the original cross-section changes its shape, which is associated with an increase in the horizontal dimension of a culvert. It is obvious that the deflection is influenced by stiffness that can be characterized by the so-called ring stiffness or flexural strength. Deformation, however, is not a free process, because the soil medium surrounding the object limits the size of the cross-section deformation (the increase in the horizontal dimension). This 
limitation is greater when the soil in the side zones of the culvert is stiffer, which depends on the type of soil and the degree of its compaction. The response to the soil pressure of the side zones of the culvert is passive pressure or soil reaction.

Thus, the value of the deformation of the underground structure made of duroplasts is not only dependent on the strength parameters of the constructional material, but also on the strength parameters of the surrounding soil.

The described cooperation of the culvert structure with the surrounding soil medium has a significant influence on the distribution of loads acting around an object. Figure 1 presents schemes of load distributions according to Drescher [6], which refer to rigid, elastic, susceptible and perfectly susceptible pipes in uniform conditions of their placement and which are subjected to the same loads.

a)

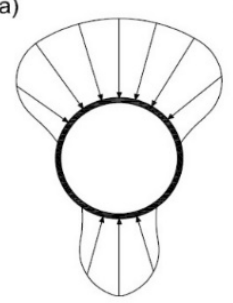

b)

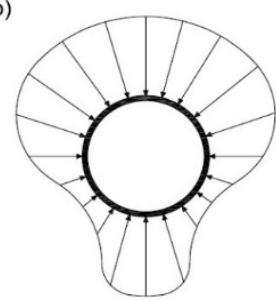

c)

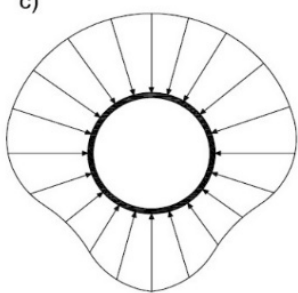

d)

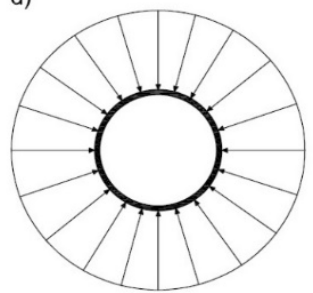

Fig. 1. Load distributions for a: a) rigid, b) elastic, c) susceptible, and d) perfectly susceptible pipes under the same foundation and loading conditions [3].

Until now, many different calculation methods have been developed that allow loads acting on constructions (mainly pipelines) arranged in the ground to be determined. For static and strength analysis of conduits, two calculation algorithms are most often used:

- a calculation method included in the German guidelines ATV A-127 [7], which takes into account the influence of the stiffness of a pipe on the distribution of loads acting on it - this method is useful for networks made of all the different construction materials,

- the Scandinavian method [8] as an analytical way of dimensioning plastic pipes, which is based on the relative short-term maximum deflection of a loaded structure - this is the basic dimensioning criterion used in this method.

Analyses of the results of calculations carried out according to different methods show that they differ substantially from each other. In some cases, the ratio between the values achieved by individual indicators differed several times. The reasons for such a state of affairs are, among others, the adoption of various variable load schemes, different values of dynamic coefficients, different soil medium parameters, as well as other differences in computational methods.

\subsection{Laboratory tests of the GRP culvert structure}

Due to the need to obtain complete information on the performance characteristics of a GRP culvert cooperating with the soil medium, a series of tests on real scale models were carried out. Culverts with a length of $6.0 \mathrm{~m}$ were installed in a soil medium. The research was carried out in 2017 at the Research Institute of Roads and Bridges in Zmigrod, Poland. The obtained results of the performed tests will be used to build a computational model that uses the finite element method (FEM). 


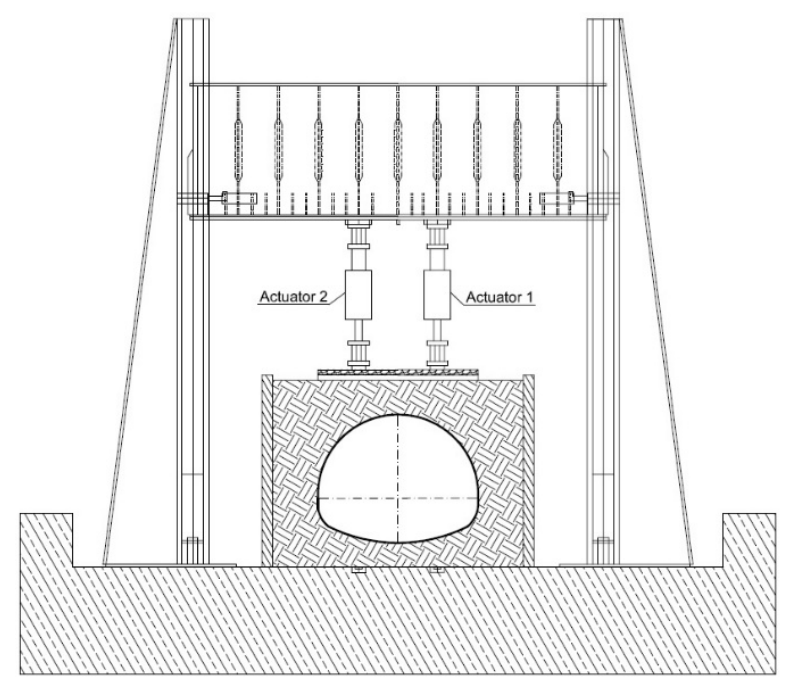

Fig. 2. Scheme of testing stand [4].

The tests were carried out for three different models of culverts, see Figure 3:

- a profile with a circular cross-section - diameter $2220 \mathrm{~mm}$,

- a profile with a bell cross-section - dimensions 3000x2400x35mm,

- a profile with a bell cross-section - dimensions 3000x $2400 \times 45 \mathrm{~mm}$.
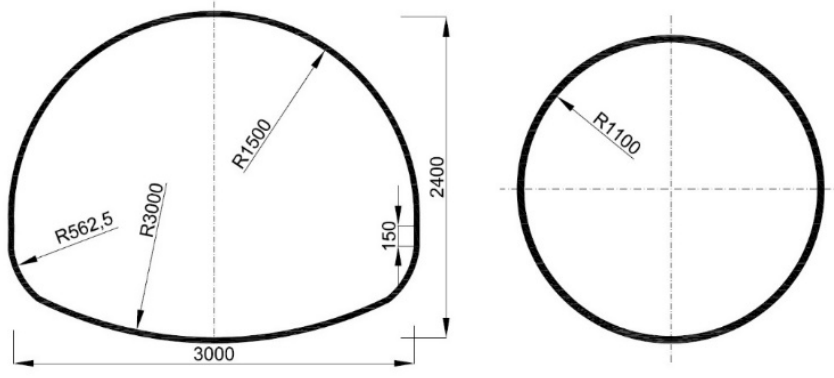

Fig. 3. Cross-sections of the tested culverts [9].

The scope of research included carrying out strength tests for loads with values and schemes adopted according to PN-EN 1991-2 [10] for variable loads caused by vehicular traffic. The load acting on the culvert was applied to a surface in accordance with the LM1 diagram in [10]. The loads were dynamic and operated in a sinusoidal cycle. The bell sections were loaded with 500,000 series of cycles, and the circular cross-sections were loaded with 100,000 cycles. Fatigue loads were obtained using two synchronized actuators.

The scope of the research included two basic stages:

1. Measurements during the covering of the culvert:

- measurements of vertical and horizontal displacements of the culvert

- measurements of deformation of the GRP material

- measurements of soil compaction IS

2. Measurements during the cyclic loading of the pipe (see Photo 2)

- measurements of the vertical and horizontal displacements of the culvert

- measurements of the deformation of GRP material 
- measurements of the stresses in the soil using electrofusion strain gauges

- measurements of the stresses occurring on the culvert surface - from the exterior and interior.

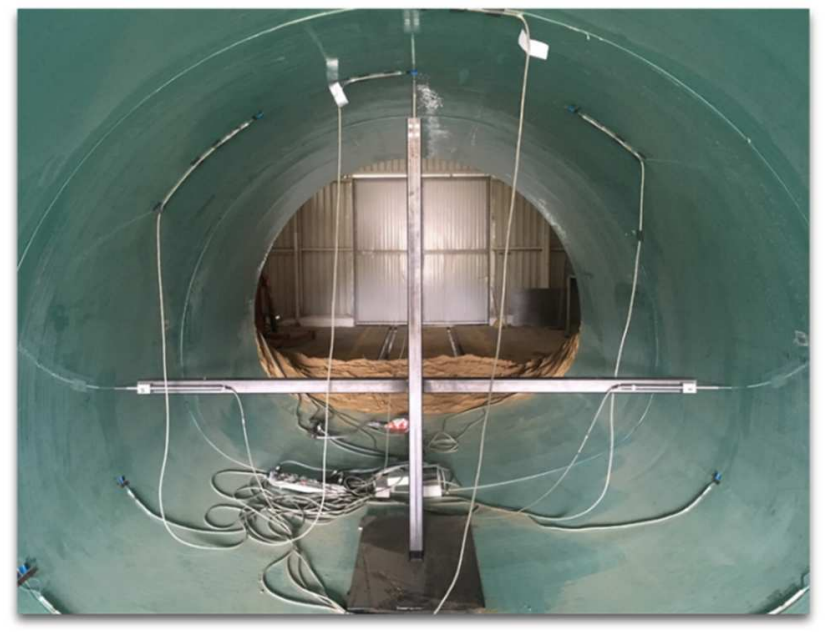

Photo 2. Meters inside the culvert [4].

The soil medium, which is a support for the culvert and plays an important function regarding the load capacity, was tested using strain gauges. The aim of the measurements was to determine the stresses in the soil medium arising as a result of external loads. The soil was additionally subjected to laboratory tests in the following scope:

granulometric composition - determining the type of soil,

ABS - direct shear apparatus - determination of the cohesion and angle of the internal friction of the soil,

anedometer - determination of soil compressibility modules (necessary to determine the value of subsidence of the soil) - modulus of elasticity of the soil substrate.

The obtained knowledge about the strength characteristics of the soil will enable the detailed parameterization of the soil medium in order to build its numerical model that uses FEM as a calculation method.

In addition, the determination of stress values that appeared in the soil medium during the course of the study will allow control analyses for the values obtained in the numerical analyses to be carried out.

\subsection{Laboratory tests}

\subsubsection{The granulometric composition}

A granulometric analysis was carried out using a sieve and sedimentation methods. The sieve analysis involves the determination of the granulometric composition of the soil by separating the individual fractions while spreading the specimen on normalized sieves. The sedimentation method is based on the process of soil fractionation in a water suspension. The idea of the method is based on Stokes's law, which specifies that the velocity of free fall of spherical particles is directly proportional to their diameter and specific density, and also depends on the specific density and viscosity of the liquid (water), as well as the earth's acceleration [11].

The graining curve, obtained as the final effect of sieve analysis, allowed the type of soil and its name to be determined. In addition, as a result of the granulometric analysis, it 
is possible to calculate the filtration coefficient, the soil's suffosionability, and to also select its optimal mixes.

As a result of the carried out soil analysis, the following fractions were isolated (according to PN-86 / B-02480 [12]): rock - 0.1\%, gravel - 8.6\%, sand - 80.5\%, dust - 7.6\% and loam $-3.2 \%$. This made it possible to classify the soil. According to the classification included in the PN-86 / B-02480 standard [12], the tested soil is clayey sand - Pg, and the classification from PN-EN ISO 14688 [13] indicates sand with loam - clSa.

\subsubsection{Determination of the cohesion and angle of internal friction}

The value of the shear strength of the soil and the internal friction angle were determined during the tests performed in the direct shear apparatus - ABS [11]. Soil shear strength is the maximum resistance of soil under shear stresses after reaching the point at which the soil structure is destroyed. The oldest and still currently used formula describing the phenomenon of soil shearing is the condition given by Coulomb in 1773 [5].

$$
\tau_{f}=\sigma_{n} * \tan \varphi+c
$$

where:

$\tau_{\mathrm{f}}$-limit tangential stresses $[\mathrm{kPa}]$,

$\sigma_{\mathrm{n}}-$ normal stresses,

$\varphi$ - internal friction angle $\left[{ }^{\circ}\right]$,

$\mathrm{c}-$ soil cohesion $[\mathrm{kPa}]$.

As a result of the conducted tests, the angle of internal friction and limit tangential stresses were determined. The following values were obtained: the angle of internal friction $-\varphi\left[^{\circ}\right]-36,1$ and limit tangential stresses $-\tau[\mathrm{kPa}]-16.7$.

\subsubsection{Determination of the soil compressibility modulus}

Soil compressibility is the ability of soil to reduce its volume when subjected to loads. Soil settlement is a process that occurs, among other things, as a result of compressibility. The compressibility modulus is a measure of compressibility, which is the equivalent of the elastic modulus of elastic solids, whereas for soil, the relationship between loads and strain is always expressed in the form of a curved line [11].

In a situation where the soil medium is the bedding (support) for the culvert, the compressibility parameters are extremely important regarding the settling process that occurs as a result of long-term variable loads. The correct determination of the compressibility value, and thus the elastic modulus for the soil is another element leading to the correct parameterization of the soil medium in the mathematical model.

\subsubsection{Tests of stresses in soil using strain gauges}

The electro-fused strain gauges use the tensoresistance effect discovered in 1856 by Thomson-Kelvin. It involves the increase of metal resistance under the influence of tensile stresses and its reduction due to the effect of compressive stresses. Strain gauges transfer strains from a loaded object. A strain gauge is bonded with the element that is being tested [14]. The applied meters, in which strain gauges were used, made it possible to read the deformation values, which were then converted into force values. As a result, it was possible to determine the stresses in the soil that appeared as a result of external loads Nine meters were used during the tests and were arranged on 3 different levels:

- level 1 - meters laid in the ground $30 \mathrm{~cm}$ above the ceiling of the culvert, 
- level 2 - meters arranged in the middle of the height for the circular section; sensors arranged in the groins of the bell section,

- level 3 - meters laid under the bottom of the structure.

The meters that were used to measure stresses in the soil were equipped with two strain gauges with a $10 \mathrm{~mm}$ measurement base, a resistance of $120 \Omega$ and a k-factor equal to 2.19.They enabled the uniaxial value of stresses occurring in each gauge during the external load operation to be determined. The meters had a circular cross-section with an outside diameter of $30 \mathrm{~mm}$. The area of soil pressure on the meter was equal to $0.00282 \mathrm{~m}^{2}$. The direct dependence from which the stresses in the soil were calculated had the following form:

$$
\sigma=\frac{N}{A}
$$

where: $\mathrm{N}$ - force $[\mathrm{kN}], \mathrm{A}-$ area of a meter $-0,00282 \mathrm{~m}^{2}$.

In order to guarantee the correct reading of stresses, each meter was tentatively loaded before its installation into the soil medium, which enabled the values of the stresses in the soil that were obtained in the subsequent phases of the cycle of loading the culvert models to be precisely determined. The results of test loads are summarized in Table 1.

Three series of readings were made for each culvert model:

- I - at the beginning of the test,

- II - for 250 thousand cycles (bell cross-sections) and 50,000 cycles (circular crosssection),

- III - for 500 thousand cycles (bell cross-sections) and 100,000 cycles (circular crosssection).

As a result of the carried out measurements for each culvert model, three series of the values indicated by the meters were obtained. Each series included 3 readings from each meter, which in total gave 27 series of readout values. The table below (Tab. 1) presents some examples of the results obtained during the tests.

Table 1. Exemplary results obtained in one measuring cycle [9].

\begin{tabular}{|c|c|c|c|c|c|c|c|c|}
\hline \multirow{2}{*}{$\begin{array}{l}\text { Meter } \\
\text { No. }\end{array}$} & \multirow{2}{*}{$\begin{array}{l}\text { Location } \\
\text { of meter }\end{array}$} & \multirow{2}{*}{$\begin{array}{l}\text { Gaugemeterreading } \\
\text { [tension/compression] }\end{array}$} & \multirow[t]{2}{*}{$\min$} & \multirow[t]{2}{*}{$\max$} & \multicolumn{2}{|c|}{ Average } & \multicolumn{2}{|c|}{$\begin{array}{l}\text { Stressesin soil } \\
\text { medium }[\mathrm{kPa}]\end{array}$} \\
\hline & & & & & {$[+] /[-]$} & {$[+] /[-]$} & $\min$ & $\max$ \\
\hline \multirow{2}{*}{1} & \multirow{6}{*}{ ceiling } & {$[+]$} & 20,00 & 150,00 & \multirow{3}{*}{21,33} & \multirow{3}{*}{151,00} & \multirow{3}{*}{3,60} & \multirow{3}{*}{24,00} \\
\hline & & {$[-]$} & 20,00 & 140,00 & & & & \\
\hline \multirow{2}{*}{2} & & {$[+]$} & 19,00 & 155,00 & & & & \\
\hline & & {$[-]$} & 22,00 & 160,00 & \multirow{3}{*}{21,33} & \multirow{3}{*}{150,00} & \multirow{3}{*}{3,60} & \multirow{3}{*}{24,00} \\
\hline \multirow{2}{*}{3} & & {$[+]$} & 25,00 & 148,00 & & & & \\
\hline & & {$[-]$} & 22,00 & 150,00 & & & & \\
\hline \multirow{2}{*}{4} & \multirow{6}{*}{ groin } & {$[+]$} & 44,00 & 200,00 & \multirow{3}{*}{42,33} & \multirow{3}{*}{201,67} & \multirow{3}{*}{6,45} & \multirow{3}{*}{30,00} \\
\hline & & {$[-]$} & 40,00 & 210,00 & & & & \\
\hline \multirow{2}{*}{5} & & {$[+]$} & 38,00 & 190,00 & & & & \\
\hline & & {$[-]$} & 40,00 & 195,00 & \multirow{3}{*}{41,67} & \multirow{3}{*}{205,00} & \multirow{3}{*}{6,30} & \multirow{3}{*}{33,00} \\
\hline \multirow{2}{*}{6} & & {$[+]$} & 45,00 & 215,00 & & & & \\
\hline & & {$[-]$} & 45,00 & 210,00 & & & & \\
\hline \multirow{2}{*}{7} & \multirow{6}{*}{ floor } & {$[+]$} & 100,00 & 390,00 & \multirow{3}{*}{100,00} & \multirow{3}{*}{391,67} & & \\
\hline & & {$[-]$} & 110,00 & 400,00 & & & 18,00 & 71,00 \\
\hline 8 & & {$[+]$} & 95,00 & 385,00 & & & & \\
\hline 8 & & {$[-]$} & 99,00 & 380,00 & & & & \\
\hline 9 & & {$[+]$} & 105,00 & 400,00 & 106,33 & 395,00 & 20,00 & 73,00 \\
\hline 9 & & {$[-]$} & 110,00 & 405,00 & & & & \\
\hline
\end{tabular}




\section{Summary}

The data obtained during the laboratory tests, with regards to the characteristics of the soil and the stresses occurring during the operation of the load, provide the basis for the construction of a numerical model that enables control calculations of culverts to be carried out. The obtained values of stresses in the soil and their distribution suggest that the limitation of the elastic space that resulted from the dimensions of the test stand had a significant influence on the work of the tested model.

The increase in stresses in the lower part of the culvert-soil cross-section was related to the decreasing thickness of the elastic medium that rested on the rigid support (the floor together with the foundation slab of the hall in which the tests were carried out). The stress values confirm that a very important issue in all types of underground constructions, in which the soil medium cooperates with the object, is its support- and not only from the side of its foundation. The proper selection of the soil and its appropriate compaction is a very important issue. A decreasing deformation capacity, and thus an increasing stiffness of the medium, causes the stresses that are indirectly induced by the external loads to increase.

\section{References}

1. A. Wysokowski, L. Janusz, Mostowe konstrukcje gruntowo-powłokowe. Laboratoryjne badania niszczace. Awarie $w$ czasie budowy i eksploatacji, XXIII konferencja naukowo-techniczna Awarie Budowlane 2007, 541-550 (2007)

2. C. Madryas, A. Kolonko, A. Szot, L. Wysocki, Mikrotunelowanie (2006)

3. C. Madryas, A. Kolonko, L. Wysocki, Konstrukcje przewodów kanalizacyjnych (2002)

4. Technical and information materials of Amiblu Company (2017)

5. Z. Wiłun, Zarys geotechniki (2013)

6. G. Drescher, Das im Erdreicheingebettetes Rohr, Osterreichischer IngenieurZeitschrift (1965)

7. ATV-DVWK-A127, Statische Berechnung von Entwasserungskanalen und -leitungen (2000)

8. J.E. Janson, J. Molin, Projektowanie $i$ wykonawstwo sieci zewnetrznych z tworzyw sztucznych (1993)

9. T. Abel, Author'sown materials (2018)

10. PN-EN 1991-2:2007, Eurokod 1: Oddziaływania na konstrukcje - Część 2: Obciażenia ruchome mostów (2007)

11. E. Myślińska, Laboratoryjne badania gruntów (2001)

12. PN-B-02481:1998, Geotechnika -Terminologia podstawowa, symbole literowe i jednostki miar (1998)

13. PN-EN ISO 14688-2:2006, Badania geotechniczne -- Oznaczanie i klasyfikowanie gruntów -- Część 2: Zasady klasyfikowania (2006)

14. Z. L. Kowalewski, T. Szymczak, Podstawy tensometrii elektrooporowej oraz praktyczne jej zastosowania, Dziewiętnaste seminaroum Nieniszczące Badania Materiałów 69-91 (2013) 